Introduction Muscle wasting, that is present in a subgroup of patients with COPD, is an independent predictor of health related quality of life and survival. The two-dimensional fluorescence difference in gel electrophoresis (2D-DIGE) technology is now recognised as an accurate method to determine and quantify proteins.

Methods and results With the aim of identifying proteins potentially involved in the process of muscle wasting, we performed 2D-DIGE protein expression profiling in the vastus lateralis of 10 patients with COPD and low fat free mass index (FFMI) $\left(\mathrm{COPD}_{\mathrm{L}}\right)\left(\mathrm{FEV}_{1} 33 \pm 4.3 \%\right.$ pred, FFMI $\left.15 \pm 0.2 \mathrm{Kg} \cdot \mathrm{m}^{-2}\right)$ in comparison with both 8 patients with preserved FFMI $\left(\mathrm{COPD}_{\mathrm{N}}\right)$ $\left(\mathrm{FEV}_{1} 47 \pm 7.3 \%\right.$ pred, FFMI $\left.19 \pm 0.6 \mathrm{Kg} \cdot \mathrm{m}^{-2}\right)$ and 9 age and gender-matched healthy sedentary subjects $(\mathrm{C})\left(\mathrm{FEV}_{1} 96 \pm 4.0 \%\right.$ pred, FFMI $20 \pm 0.9 \mathrm{Kg} \cdot \mathrm{m}^{-2}$ ). Data analysis was performed using DeCyder software and for protein identification MALDI_TOF mass spectrometry (MS).

Ten proteins, whose expression was significantly changed in $\mathrm{COPD}_{\mathrm{L}}$, were identified; serum albumin (ALBU), heat shock protein beta-1 (HSPB1), peroxiredoxin-6 (PRDX6), Alpha-crystallin B chain (CRYAB) and Alpha-1-antitrypsin (A1AT) were increased while Histone-lysine N-methyltransferase (DOT1L), Troponin T (TNNT1), Myozenin-1 (MYOZ1), Myosin light chain 1 (MYL1) and mitochondrial ATP synthase subunit alpha (ATPA) were decreased.

Conclusion Our results showed a down-regulation of structural muscle proteins, proteins involved in myofibrillogenesis, cell cycle arrest and energy production and up-regulation of proteins reacting to cell stress and proteins involved in oxidative stress protection.

Supported by Chief Scientist Office (CSO) Scotl06/S1103/5 and FIS PI08/0320.

\section{S143 PREMATURE AGEING AND SKELETAL MUSCLE DYSFUNCTION IN COPD PATIENTS: DEVELOPMENT OF A CELL CULTURE MODEL}

${ }^{1} R$ Lahkdar, ${ }^{1} G$ Choudhury, ${ }^{1} J$ McLeish, ${ }^{1} E M$ Drost, ${ }^{2} L$ McGlynn, ${ }^{2} P G$ Shiels, ${ }^{1} W$ MacNee, ${ }^{1}$ RA Rabinovich. ${ }^{1}$ Edinburgh Lung and the Environment Group Initiative (ELEGI), Centre for Inflammation and Research, Queens Medical Research Institute, Edinburgh, Edinburgh, UK; ${ }^{2}$ University of Glasgow, College of Medical, Veterinary and Life Sciences Institute of Cancer Sciences, Glasgow, UK

\subsection{6/thoraxjnl-2014-206260.149}

Introduction COPD is a disease of accelerated ageing, as increased cellular-ageing (senescence) occurs in the lungs of these patients. We aim at developing a primary skeletal muscle cell culture (Human skeletal muscle satellite cells [HSKMC]) model of muscle ageing to study the cascade of events that occur in muscle senescence in vitro and to explore the effect of inflammation (TNF alpha) and oxidative stress $\left(\mathrm{H}_{2} \mathrm{O}_{2}\right)$, two of the putative mechanisms related to muscle dysfunction and/wasting, on muscle differentiation and on protein loss in differentiated cells. Methods and results HSKMC were cultured to senescence when the cells stopped replicating. DNA was isolated from cells in serial passages of culture. Telomere length, a marker of biological ageing, was measured by qPCR and expressed as the ratio of telomere repeat copy number to single gene copy number in the experimental sample relative to a control sample (relative $\mathrm{T} / \mathrm{S}$ ratio) $(\mathrm{n}=3)$. Preliminary results show a progressive shortening of telomere length with cellular ageing when comparing early (passage 2, $1.433 \pm 0.05$ relative $\mathrm{T} / \mathrm{S}$ ratio) with a later passage (passage 15, $0.340 \pm 0.2$ relative $\mathrm{T} / \mathrm{S}$ ratio) (Fig 1).

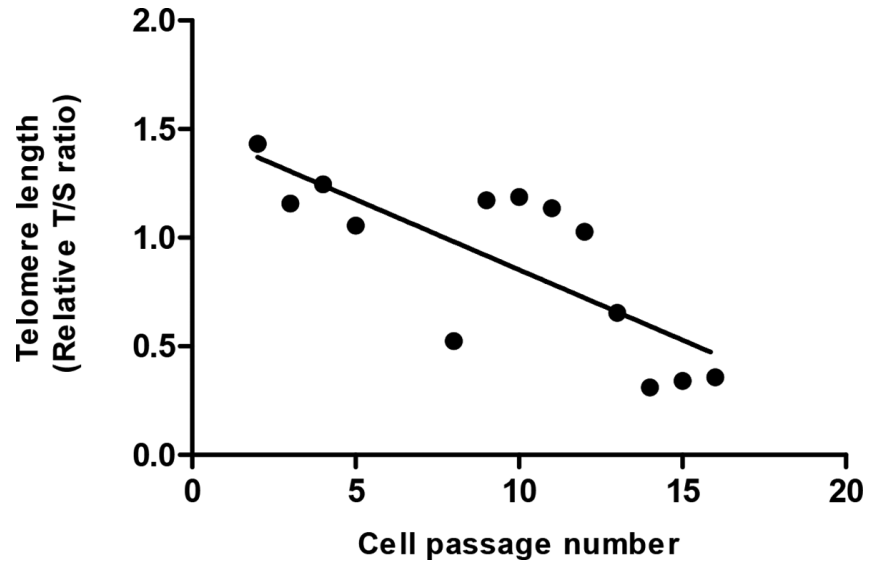

Abstract S143 Figure 1 Telomere Length analysis in HSKMC

Conclusion We have developed a novel in vitro model of ageing skeletal muscle cells, which will help us to assess the role of accelerated ageing in muscle dysfunction and/wasting in COPD patients.

Dr Lakhdar was funded by an LTERS fellowship grant.

\section{S144 QUALITY OF LIFE IN IDIOPATHIC PULMONARY ARTERIAL HYPERTENSION IS ASSOCIATED WITH QUADRICEPS FUNCTION AND SIZE}

${ }^{1} \mathrm{BE}$ Garfield, ${ }^{2} \mathrm{~L}$ Parfitt, ${ }^{2} \mathrm{C}$ Harries, ${ }^{2} \mathrm{~K}$ Dimopoulos, ${ }^{1} \mathrm{M}$ Gatzoulis, ${ }^{1} \mathrm{P}$ Kemp, ${ }^{1} \mathrm{Ml}$ Polkey, ${ }^{1} \mathrm{SJ}$ Wort. ${ }^{1}$ Imperial College London, London, UK; ${ }^{2}$ Royal Brompton Hospital, London, UK

\subsection{6/thoraxjnl-2014-206260.150}

Introduction Despite recent improvements in therapy patients with idiopathic pulmonary arterial hypertension (IPAH) still suffer with significantly reduced quality of life (QOL). Muscle dysfunction and low physical activity are emerging as important complications of the disease. Separately rehabilitation programs have been shown to cause an improvement in both QOL and muscle strength but the direct relationship between these factors has not as yet been documented in this condition.

Aims We aimed to define the relationship between QOL and muscle function, size and physical activity in patients with IPAH. Methods In 12 patients with IPAH we measured quadriceps maximal volitional capacity (QMVC), ultrasound cross sectional area of the rectus femoris (US $\mathrm{RF}_{\mathrm{RF}} \mathrm{CSA}$ ), fat free mass index by bioelectrical impedance (FFMI), physical activity using the Sensewear armband (steps per day, total energy expenditure (TEE), and active energy expenditure (AEE)). They were also asked to complete the St. George's respiratory questionnaire (SGRQ). Correlations were performed with Pearson's or Spearman's test.
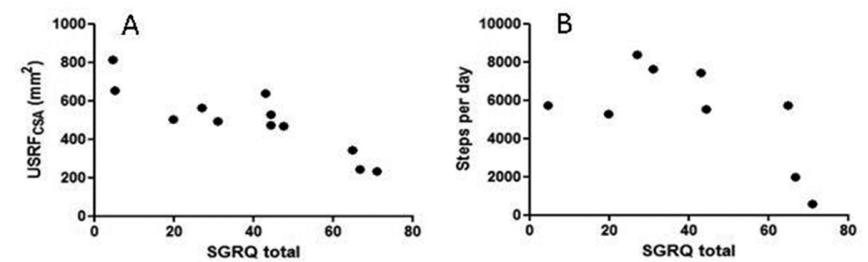

Abstract S144 Figure 1 St. George's respiratory questionnaire total score plotted against $A$ : Ultrasound rectus femoris cross sectional area $\left(U_{S R F} F_{C A}\right)(n=12$, Spearman's $r=-0.88, p=0.0002) ; B$ : Steps per day $(n=9$, Spearman's $r=-0.61, p=0.08)$; in patients with IPAH 